Markers of Assimilation of Problematic Experiences in Dementia within the LivDem project.

Richard Cheston, Lauren Gatting, Ann Marshall, John Spreadbury and Peter Coleman

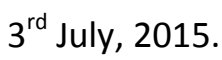

Requests for reprints should be addressed to:

Richard Cheston,

Centre for Health and Clinical Research,

Department of Health and Social Sciences,

Glenside Campus,

University of the West of England,

Stapleton Road,

Bristol,

BS16 1DD

tel: 0117-3288927;

e-mail: Richard.Cheston@uwe.ac.uk

Word count: 5,500

Keywords: dementia, Alzheimer's disease, group psychotherapy, assimilation, awareness 
Acknowledgements - We would like to thank all of the participants and their families for participating in this research. The project team would also like to thank the group facilitators (Kathy Chapman-Hill, Jackie Shearing, Lorraine Conduit, Rachel Crane, Angela Lynch, Kate Wilson, Rebecca Burke, Heather Baldwin, Rachel Woodward, Alison Moren, Sue Ward, Helen Williams, Debbie Bolton, Emma Reed, Susan Ryan and Nicki Short).

Note about funding. This article presents independent research funded by the National Institute for Health Research (NIHR) under its Research for Patient Benefit (RfPB) Programme (Grant Reference Number PB-PG-0610-22005). The views expressed are those of the authors and not necessarily those of the NHS, the NIHR or the Department of Health. Trial Identifier: ISRCTN25079950 


\section{Markers of Assimilation of Problematic Experiences in Dementia within the LivDem project.}

\section{Abstract}

This study aimed to determine whether the Markers of Assimilation of Problematic Experiences in Dementia scale (MAPED) can be used to identify whether the way in which participants talk about dementia changed during the group.

All eight sessions of a LivDem group which were attended by participants were recorded and transcribed. An initial analysis identified 160 extracts, which were then rated using the MAPED system. Inter-rater reliability was 61 per cent and following a resolution meeting, 35 extracts were discarded, leaving 125 extracts with an agreed marker code.

All of the participants were identified as producing a speech marker relating to dementia, and these varied between 0 (warding off) to 6 (problem solution). Examples of these markers are provided. The proportion of emergence markers (indicating the initial stages of assimilation) compared to later markers changed significantly between the first four sessions and the final sessions. This difference was still significant even when the markers produced by the most verbal participant, Graham, were excluded. The use of process measures within psychotherapy complements more conventional outcome measures and has both theoretical and clinical implications. 


\section{Markers of Assimilation of Problematic Experiences in Dementia within the LivDem project.}

\section{Statement of ethical approval}

The protocol was registered on line (http://www.controlled-trials.com/ISRCTN25079950/), and received approval from NRES Ethics Committee South Central - Oxford B (REC Number 11/SC/0363, approval dated 18th November 2011, accepted protocol amendments on $28^{\text {th }}$ June 2012 and $23^{\text {rd }}$ August 2012).

\section{Background}

The Assimilation Model of psychotherapeutic change (Honos-Webb \& Stiles, 1998; Stiles, 1999; 2001; Stiles et al, 1999) is a transtheoretical model of the process of change that occurs in psychotherapy. The Assimilation Model is not a description of how to do therapy, but rather a way of formulating the nature of change that can occur in any form of therapy, or indeed, in everyday life. It has been used to analyse the process of change within psychotherapy sessions with clients with a wide variety of mental health needs (e.g. Varvin \& Stiles, 1999), as well as people with learning disabilities (Newman \& Beail, 2002) and people affected by dementia (Watkins et al, 2006).

The assimilation model represents the self not as a single, unified entity but instead as contextdependent, shifting and multiple selves. This is consistent with post modern or social constructionist theories of the self which describe a "community of voices" (e.g. Hermans \& Kempen, 1992; Mair, 1989; Gergen \& Kaye, 1992). Typically, these different voices are referred to as the Dominant Voice (the voice of continuity, or the preservation of the status quo) and the Problematic Voice (the voice of the emotional consequences of change including fear, anger, sadness and loss). Within the Assimilation Model, most experiences in a person's life are seen to be unproblematic and can be assimilated relatively routinely into that person's existing self.

During successful assimilation, a dialogue or conversation occurs between the Problematic and Dominant Voices (Honos-Webb \& Stiles, 1998), leading to the resolution of the differences between the two voices. However, some experiences are so traumatic and their implications are so 
threatening that they represent a profound threat to that person's sense of self. In these cases, conflict arises between the different voices which acts to prevent the assimilation of that experience, and the unassimilated material remains unacknowledged or "warded off" (Honos-Webb \& Stiles, 1998; Stiles, 2001). Within this model of psychotherapy, the role of therapy can thus be understood as being to facilitate a conversation between the Problematic and the Dominant Voices thus enabling the person to engage with the difficult or problematic material, and to integrate this otherwise unassimilated material. This often takes the form of the client approaching and then retreating from the threatening material.

The assimilation model recognises the dynamic nature of how change may occur both in the way in which people talk about their problems and the affective intensity with which they do so (Varvin \& Stiles, 1999). This process of change is represented in terms of eight incremental levels (see Table 1 ). The emotional quality of the different levels is central to this model of change. As the Problematic Voice is articulated increasingly clearly, so the person moves away from a defensive posture of warding off problematic material, to experiencing the content as increasingly painful. In later levels, as the Problematic Voice is integrated or assimilated into the self, so solutions are tried out, confidence grows and the distressing emotions associated with the material are worked through (Newman \& Beail, 2002). Each of the eight levels is characterised by a number of specific speech markers (Honos-Webb et al, 1998, 1999) which are indicative of the form of dialogue that occurs at the different levels between the Dominant and the Problematic Voice. This process has been formalised through the development of the Markers of Assimilation of Problematic Voices Scale or MAPVS (Honos-Webb, Stiles and Greenberg, 2003). The MAPVS is primarily a research tool, but it can also be used to help to formulate clinical problems, and as such has strong clinical relevance (Stiles, 2001).

\section{INSERT TABLE 1 ABOUT HERE}


Assimilation and Dementia. The threat of a dementia diagnosis can be understood in terms of the Assimilation Model of Problematic Voices. Within this framework, a diagnosis is likely to represent such a powerful threat to the person's psychological equilibrium that it may resist being easily assimilated into the self. This way of representing the threat of dementia, and thus the nature of the psychological change that is required for people to "come to terms with" dementia, has been used in a series of studies about changes in descriptions of dementia (e.g. Snow, Cheston and Smart, 2014; Cheston, 2013; Betts and Cheston, 2012; Simms and McCrum, 2012; Watkins et al, 2006; Cheston, Jones and Gilliard, 2004). The Markers of Assimilation of Problematic Voices Scale (MAPVS) was adapted so that it is appropriate for use with people with dementia (Lishman, Cheston and Smithson, 2014). The revised scale (known as the Markers of Problematic Experiences of Dementia or MAPED scale ${ }^{1}$ ) follows the MAPVS by coding accounts of dementia in terms of a series of markers, or speech events, which can be grouped into one of eight possible levels (see Table 1). Ratings of these markers take into account both the use of language to frame dementia (and dementia-related experiences) and the emotional intensity that surrounds this discourse. Adapting the MAPED scale from the original MAPVS involved identifying passages from either psychotherapy groups or qualitative interviews with people affected by dementia in which descriptions of dementia were initially rated as indicative of a specific marker and then used as illustrative templates to guide future analysis. For instance, a passage would be coded as falling into level 1 (unwanted thoughts) if the account includes an aspect of dementia such as memory loss and the person's level of affect indicates feelings such as anxiety, anger or sadness. In addition, there needs to be a strong sense that exploration of the wider implications of the dementia are being avoided because this is experienced as being frightening or destabilizing to the person's emotional equilibrium. Level 1 markers include: changing the conversation; locating the existence of dementia elsewhere by talking about other people and not themselves as having dementia; limiting the problems the person experiences to some areas without this being explicitly or implicitly associated with dementia;

\footnotetext{
${ }^{1}$ The MAPED coding frame is attached to this paper as a supplementary material
} 
references to fears of being mad or abnormal; asserting that other areas of functioning are unimpaired or that they can be easily overcome; or other speech acts that minimize the significance of the dementia experience.

One marker of a level 1 rating that was identified in the original MAPVS rating process is referred to as the "fear-of-loss-of-control" marker (Honos-Webb, Lani and Stiles, 1999). This marker can be identified as occurring when a person describes a choice between continuing to explore the problematic experience (and risking destabilising their internal, emotional equilibrium), and avoiding further discussion. The clinical importance of this marker is that it signifies the emergence of unwanted thoughts into the person's awareness, an early indication of the person beginning to assimilate emotionally charged or problematic experiences. The MAPED coding frame translates this into the context of dementia by identifying instances in which a person avoids discussing dementia, for fear of how of what this might make them feel. Thus, in the psychotherapy group subsequently reported by Watkins et al (2006), Mr E states "I can't think about coming here, it just brings it all back".

One indication of a possible "fear-of-loss-of-control" marker can be found in what has been described by Cheston (2015) as the Voldemort phenomenon. This refers to the way in which some people affected by dementia may refer to aspects of their experiences indirectly, and without using the terms "dementia" or "Alzheimer's disease". Just as in the Harry Potter series of novels, the evil Voldemort is for many characters too frightening to be named directly, so too some people affected by dementia find their illness too powerful to be referred to by name. To name dementia, then, is to acknowledge its existence and thus to risk a loss of emotional equilibrium. Thus Sue's description of her dementia as "like being given a ticking time bomb" (Snow, Cheston and Smart, 2014) and Henry's analogy of fighting an unnamed foe because he did not want to "wave the white flag" (Lishman, Cheston and Smithson, 2014) were both rated being markers of a "fear-of-loss-of-internalcontrol" - and thus acquired a Level 1 rating. Finding alternative ways to talk about dementia, for 
instance by using euphemisms (such as memory loss) or figurative language is therefore part of a process of emotional regulation.

Living well with Dementia therapy groups. The Living well with Dementia (LivDem) group therapy project was a pilot randomised control trial, which compared the impact on people who have recently received a diagnosis of dementia of attending a therapy group compared to a waiting-list control group. Seven groups were established across the south of England, each of which lasted for ten weeks and involved memory clinic staff delivering a manualised intervention (see Table 2 for details of the course content). Sixty participants were randomised to receive either the intervention or usual care in the form of a waiting list control arm. The analysis of data arising from the study involved both quantitative and qualitative components. The collection of outcome measures at baseline, the end of the study and follow up was complemented by the assimilation analysis of changes in how participants talked about their problems. These two strands of analysis were included in the study protocol, with the recording, transcribing and analysis of material from the sessions being specified in the consent process. For the primary outcome measure of quality of life and a secondary outcome, self-esteem, there were strong, but non-significant trends towards improvement in the intervention group compared to the control group (Marshall et al, 2014). This is consistent with previous research which has indicated that short-term group therapy or support intervention can be effective in lowering levels of depression (Cheston, Jones and Gilliard, 2003; Cheston and Jones, 2008; Logsdon et al, 2010). However, as a pilot study, the research was not powered to produce significant findings, and these results thus need to be treated with caution.

\section{INSERT TABLE 2 ABOUT HERE}

The aim of the LivDem intervention is to support people who have recently received a diagnosis of dementia to plan ahead and to take control over their illness. For many people, this may present a significant emotional challenge in which there is a need, in effect, to balance the practical benefits that might accrue from greater understanding of dementia on the one hand, against the existential 
pain that might arise from this increase in awareness (Cheston, 2013). The aim of the qualitative part of the study was to establish whether it was possible to use the MAPED technique to identify whether there were changes in the type of markers that are found over the course of one of the LivDem groups.

\section{Method}

The assimilation analysis of recordings collected during the LivDem study falls into two parts: first of all, the analysis presented here of all eight of the sessions attended by one of the seven groups; and secondly, the analysis of a randomly selected sample of sessions from the remaining six groups, which will be reported separately. The group from which this analysis is presented was the first of the seven groups to take place, although otherwise it does not differ significantly from the other groups that were part of the project.

All names used here are pseudonyms. The group was initially made up of five participants, one of whom (Ellen) was only able to attend the preliminary session with her husband, as she subsequently slipped at home and broke her arm. All of the four other participants attended every session (see Table 3 for details). Although each group consisted of 10 sessions, the first and final sessions had a different format: they involved not just group participants but a relative or friend also attended. As the dynamics within these two sessions were different, they have not been included in this analysis. All eight sessions from one of the seven groups that were part of the project and which involved only participants were recorded and transcribed (although only 15 minutes of session one were recorded due to technical difficulties).

\section{INSERT TABLE 3 ABOUT HERE}

The procedure for identifying markers of assimilation is adapted from psychotherapy process research (Honos-Webb \& Stiles, 1998; Honos-Webb et al, 1999; Knobloch et al, 2001). This consists of four steps: 
- Transcribing and familiarisation. All participants in the LivDem study gave their consent for each session to be audio-recorded. The initial step of the analysis involves intensive exposure to the transcripts, making systematic notes to locate passages that relate to change, cognitive loss or expressions of heightened affect.

- Extracting passages. Speech markers are identifiable events in discourse that recur throughout the transcripts and that indicate important clinical phenomena (Honos-Webb et al, 1998). In this analysis LG identified 160 extracts in which one or more of the group participants either referred directly to an aspect of dementia or were provided with a clear opportunity to do so (e.g. through a question by a facilitator) but avoided doing so.

- Rating passages. LG was trained using extracts that had initially been rated in Lishman, Cheston and Smithson (2014). LG and RC then independently coded the extracts. RC was blind to the session in which the extracts occurred, although LG was not blind as she had extracted the data from the transcripts. There was an initial agreement on 98 of the 160 extracts, giving an interrater agreement level of 61 per cent.

- Clarifying disagreements. The 62 ratings where the raters disagreed, were discussed in a resolution meeting. This enabled agreement to be reached for 27 extracts, with the remaining 35 extracts being discarded as they were deemed either not to have enough content to be rated or as being too difficult to be rated reliably. This left a combined total of 125 extracts with an assigned marker code

\section{Results}

Across the eight sessions as a whole, markers from every level except Level Seven (Mastery) were identified. Over half of the extracts (66 of the 125) came from one participant: Graham. Previous research (e.g. Cheston, 2013) suggests that the markers can be sub-divided into three groups: emergence, in which the therapeutic task is to enable dementia to emerge as the cause of problems 
without the person being overwhelmed (Levels 0, 1 and 2); naming dementia as the problem and finding distance from it (levels 3 and 4); and working through (levels 5, 6 and 7)

\section{A. EMERGENCE}

LEVEL 0: warding off. In session 2, when the group was asked directly about how their memory problems affected them, Mary showed avoidance by interpreting the question as relating to her physical disability:

[1] Mary: I've come to terms with mine now I know I can't walk on my leg again so yeah I've come to terms with it now. Session2 For an extract to be identified as a Level 0 marker, the person needs to actively avoid discussing dementia, or any subject related to dementia, or to reject the possibility that dementia plays a role in their life. Often this is by attributing any changes in life to the effects of age or to a physical or sensory impairment. Thus, in this group when Mary was asked to engage personally with issues around memory loss which arose in the initial sessions, she attributed her difficulties in life to her physical health problems (she used a wheel chair). Her affect was minimal suggesting that she had successfully avoided the problem and her replies tended to close down further discussion.

LEVEL 1: unwanted thoughts. For a speech extract to be rated as occurring in this level, there needs to be evidence both that the person has thought about dementia, and also that these thoughts are actively avoided. Thus in the fifth session, the group watched a recording of people talking about how the diagnosis of dementia had affected them personally. Mary who had been quiet, was asked about the impact of the dementia diagnosis on her:

[2] F1: How did you feel about it Mary?

Mary: Oh I feel all right about it, me. Yeah.

F2: So did, when you had your diagnosis did it // Mary: //Hmm?

[2.1] F2: When you had your diagnosis did it affect you in any way? Mary: No, no, no

F2: No.

[2.2] Mary: No, I said well if I was dying or something like that [2.3] you've got to carry on, 


\section{there's no good moan}

[2.4] no use sitting there thinking about it is there

[2.5] So I just carry on what I can do

I can't get up and walk I know but (coughs)

you know I'm sat there and I do a lot of um

crosswords and things that keep my mind occupied.

Session 5

Thus Mary acknowledged that she had been diagnosed (with Vascular Dementia), but then denied it had affected her (2.1) and minimized the impact on her "if I was dying or something like that" (2.2).

Two features of this extract are typical of a Level 1 marker: first, the expression of the need to ignore the Problematic Voice, as Mary repeats the phrase "carry on" (2.3.and 2.4); and secondly, the Problematic Voice is referred to only indirectly as "no use sitting there thinking about it is there" (2.5). At this point in the therapeutic process, clients are faced with a psychological dilemma: to continue to explore the emerging, threatening areas of their life (and thus risk the escalation of distress), or to continue to push this difficult material away. As has been detailed above, the therapeutic significance of the fear-of-loss-of-control marker (a level one marker) within therapy has been explored both within general psychotherapy (Honos-Webb, Lani and Stiles, 1999) and within therapy for people with dementia (Cheston, 2015). Emerging affect can involve stronger negative feelings such as anxiety, fear, anger and sadness, but these are typically controlled and spoken of as being pushed away.

LEVEL 2: vague awareness. In this level, the person is in distress that comes from an internal conflict relating to an aspect of their dementia. In articulating this distress, the person seems to be caught up in the moment of the emotion. They express material with a strong level of affect, and while the nature of this affect varies, nevertheless there is a clear intensity to the way in which they express themselves. Thus, in this series of extracts, the participants express their distress which we might characterize as, respectively, sadness, resentment and anxiety:

[3] F1: You're really quiet there Gina.

Gina: Yeah I know, there's lots of things going through my mind. Not always good Graham: I'm sorry if I've//

Gina: //No, no, it's nice to hear anyway. 
[4] Graham: And before long they'll be giving you toilet paper and wiping your bum for you. Gina: I don't want that

[5] Gina: My memory turns up at the wrong times

In the middle of the night

I'm awake then thinking

oh my god I didn't do that

I didn't speak to them

Session 7

In all three extracts. Gina and Graham are caught up in the emotion of their distress. In this sense, they are talking from within their emotion, rather than being able to stand outside it and talking about their distress, both of which are characteristic of markers at later levels of assimilation.

\section{B. NAMING DEMENTIA AS THE PROBLEM}

LEVEL 3: clarifying dementia as the problem. At this level the person both acknowledges the existence of a problem and attributes this to or recognizes that this is caused by their dementia. Thus, in session five Gina and Graham comment on a recording of people talking about a diagnosis of dementia that they had just watched (this was part of a DVD used within sessions):

[6] Facilitator 1:...You were watching the television just now people were talking about how they felt when they first had their diagnosis.

Gina: It does it makes you feel you know that you're going downhill very fast. Graham: That's right

$$
\text { it makes you feel that it's far more serious than you imagined it to be }
$$

At this level, people describe or talk about their reaction to the knowledge that they have dementia (e.g. feeling upset, silly, angry or trying to cover up for mistakes) but without being caught up in the emotion of this as was the case with the Level 2 markers. Although at times the person may feel 'stuck' and to see no way out of their problem, they are beginning to be able to stand back from the problem and talk about it, rather than being overwhelmed by the distress, as is the case in Level two markers. For example, they may ask questions about the problem or express curiosity about the problem in order to aid their understanding. Thus in the final session (week eight), Graham asks about the issue of sun-downing:

[7] Graham: You, fortunately for me brought up an area which was snowboarding. 
I1: Oh, sun downing?

Graham: Sun downing sorry sun downing

I happened to say that that's something I get

now what I then went on to say is

is that something that's going to get worse?

is it going to get better

is it going to stay as it is?

it's the broadening of more than just memory.

LEVEL 4: understanding and gaining perspective. In this level, the person acknowledges the

existence of a dementia or a central aspect of dementia such as a memory problem but is also able to describe how this makes them feel, or how they react to this. However the central feature of this level is the way in which the person is able to stand back from their feelings and from the diagnosis they have achieved some emotional distance from the dementia even though they recognize that it affects their life at times profoundly. Consequently, the person's affect is mixed-for instance there may be a tone of relief in addition to distress, or the person may show that they have achieved some emotional distance from the dementia, rather than being overwhelmed by it, by making a joke or laughing. Thus in the final session, Graham both describes his concern at being a burden on his wife, but makes light of this:

[8] Facilitator 1: ...is that a concern as well

the fact that maybe other people will see changes happening and you won't see those changes?

Graham: my concern if you want to know the real truth is at what stage am I going to be a real burden on my wife.

F1: Right yeah.

Graham: That's my real concern.

F1: Yes have you shared that at all with your wife have you talked to her?

Graham: She wouldn't accept it if I did.

F1: Really.

Graham: She would tell you I am already a burden (laughs)

Gina: In a joking way probably?

Graham: (laughs) No seriously

Session 8

\section{WORKING THROUGH}

LEVEL 5: accepting dementia and developing strategies. Here, the person acknowledges the existence of a dementia or a central aspect of dementia such as a memory problem and recognises 
that the dementia cannot be cured, but can be managed. They can point out exactly what needs to change or to be worked on and show that they are weighing up attempts at specific or partial solutions to the problem (e.g. considering taking medication, supporting the Alzheimer's society or challenging stigma). The affect (mood) is positive, business-like and optimistic. Thus Graham comments in the penultimate session:

[9] Graham: I was told I had dementia

and the best thing I could do was tell everybody

I've done exactly that

I've told everybody that

If I could tell you the truth

I don't think they've taken one blind bit of notice

Session 7

LEVEL 6: problem solution. At this level the person is able to acknowledge that they have dementia and describe having achieved a change in their life in living with dementia that they feel positive about. This change may be in their understanding of what is happening to them or they may talk about a change in their relationships with others, or comment on how others have noticed that they have changed. Thus in session six, Graham's affect is positive, satisfied and proud of his accomplishment:

[10] Graham: Well I try and be jolly all the time and I keep thinking to myself

I should have made a change by now because when I was told I got dementia it was as if you know the end of the world had come where as far as I'm concerned I'm not on so many tablets I'm probably jollier not necessarily happy but jollier that I've been for years

Does that make sense? Session 6

Shifting use of markers across sessions.

\section{INSERT FIGURES 1 AND 2 ABOUT HERE}

This analysis shows that the levels of markers used in sessions altered as the group progressed. As Figure 1 indicates, there was a shift towards an increase in the proportion of markers from more 
assimilated levels in the later sessions. Alongside this was a decrease in markers signifying emergence of awareness (i.e. levels 0,1 and 2 ) as there are no level 0 markers after week 2 , no level 1 markers after week five, and only one level 2 marker in each of sessions six, seven and eight. Similarly, there was an increase in higher level markers over successive sessions: from week four onwards, there was a significant increase in the number of markers from levels $3,4,5 \& 6$. A $2 \times 2$ contingency table was constructed to examine whether there were differences between the proportion of markers indicating an emerging awareness (Levels 0, 1 and 2) and more assimilated markers (levels, 3, 4, $5 \& 6$ ) between the first four and the final four sessions. Fisher's exact test gave a highly significant two-tailed value of less than 0.0001 . Over half of the extracts (66 of the 125) came from one participant: Graham. However, although Gina, Mark and Mary provided fewer references to dementia that could reliably be identified as markers, nevertheless Figure 2 suggests that when they did contribute, then their use of markers too altered. Even when Graham's markers were excluded from the contingency table, Fisher's exact test gives a $P$ of 0.0016 .

\section{Discussion}

This study set out to test whether the markers that were used within a therapy group changed across the eight participant-only sessions of a group. We have argued that the Markers of Assimilation of Problematic Experiences of Dementia is a useful way of tracking change, and also that in the second half of the group, participants talked about their dementia in a different way to that in the first four sessions. Change is still present even when Graham, the most verbal and assimilated participant is removed from the analysis.

There are two possible reasons for this apparent change in levels of markers found in the group over the initial and latter stages of the group: either it may represent a therapeutic shift in which participants gradually assimilated the problematic elements of their diagnosis; or alternatively, it may reflect the way in which the topics that the facilitators raised altered across these sessions. In many ways, this change in the type of markers used probably reflects both of these factors - thus 
although the facilitators talked more directly about dementia in later sessions, participants were able to assimilate this understanding in a way that may well have not have been possible at an earlier point. Indeed, it is this combination of participant and therapeutic factors that typifies the psychotherapeutic process of change.

In addition, talking about dementia, was rarely characterised as existing at a single level of assimilation. Instead, individuals moved between different levels within the same session, and sometimes within the same extract. This is a process that has been described elsewhere, for instance within qualitative analysis of interviews with people affected by dementia. Typically, these studies represent awareness as a fluid process in which both denial and acknowledgement of dementia may be present. Thus Robinson, Clare and Evans (2005) described couples' shared constructions of the diagnosis of dementia as a process that cycled through "denial, minimisation and gradual realisation as couples gradually began to accept the changes in the person with dementia were likely to be permanent, linked to an oscillating process of acknowledging what had been lost, as well as carrying on as a couple by focusing on what remained for each person and the couple." (Robinson, Clare \& Evans 2005, p344).

Importantly, both the growth in awareness for some participants and the oscillating ambivalence described by both Robinson, Clare and Evans and by Lishman, Cheston and Smithson (2013) occurred outside a formal psychotherapeutic process. This suggests that for some people affected by dementia it is possible to gain increased awareness of their illness without attending support groups such as LivDem. However, the personal and social characteristics that lie behind such shifts in awareness are not clear.

Implications for clinical development. Drawing on the assimilation model, Cheston (2013) has suggested that there are three steps within this process of adjusting to the illness. The first task is for people to be able to name their problems as being dementia without being emotionally overwhelmed (levels 0, 1 and 2). Then, once people are able to talk about the dementia, they have 
to find some emotional distance from the illness (levels 3 and 4). Finally they are able to see dementia as only one part of their lives, and make appropriate plans (levels 5, 6 and 7).

Within this model, the transition between levels 2 and 3 (i.e. from warding off awareness of the illness, to identifying dementia as the problem) is of critical importance. This process involves the person managing to name their problems as being caused by dementia without, at the same time, being emotionally overwhelmed. Intrinsic to this change in talking about dementia is an emotional process involving the person articulating the Problematic Voice. This may be around their fears for the future, around loss (such as giving up driving) or around embarrassment and frustration. From a clinical perspective, what seems to facilitate people in approaching their dementia includes other people in the group articulating their fears and concerns (Watkins et al, 2006) and using indirect ways of exploring threat (Cheston, Jones and Gilliard, 2004). Conversely, barriers to change may be setting too fast a pace for therapy, providing information at too soon a point in the therapeutic process or involving people from outside the group (Cheston and Jones, 2009).

Implications for research. The Assimilation Model has a number of differences compared to other approaches which examine the awareness that people affected by dementia have into their illness. One clear difference is the way it conceptualises the relationship between affect and awareness as a complex and bi-linear process. Thus the Assimilation model suggests that initially increased levels of awareness from warding off (Level 0) through to Vague Awareness (level 3) are associated with increasing levels of affect. This distress can be dissipated through the use of affect regulation behaviours such as repression and the projecting out of distress, but it may also be associated with behavioural strategies such as avoidance. For some people increased awareness of the Problematic Voice of dementia may be associated with verbal markers of a fear-of-loss-of-control in which the person expressed concerns that continuing to engage with the problematic material may lead to a loss of psychological equilibrium or well-being (Cheston, 2015). However, if the person affected by dementia is able to continue to articulate their Problematic Voice and this becomes assimilated into the community of selves, then levels of affect decline. Thus if a person is able to identify their 
problems as being associated without being emotionally overwhelmed and are both to hold onto their dementia while also identifying partial solutions to some of the problems that it raises, then levels of affect diminish.

Final thoughts. The importance of post-diagnostic support for people affected by dementia is increasingly recognised (Watts et al, 2014). The Living Well with Dementia groups provide a shortterm intervention that can be facilitated by nurses and other memory clinic workers after a two day training course and receiving supervision from Clinical Psychologists. Although evidence from the Pilot study was encouraging, further work is needed to clarify its therapeutic impact. This includes identifying whether participants are more able to acknowledge their dementia as a result of attending the groups, and to identify therapist behaviours that facilitate or impede this process. The MAPED method provides an innovative and potentially important way of tracking therapeutic change or growth in awareness, and this is an important tool in both research and clinical practice. 
Acknowledgements - We would like to thank all of the participants and their families for participating in this research. The project team would also like to thank the group facilitators (Kathy Chapman-Hill, Jackie Shearing, Lorraine Conduit, Rachel Crane, Angela Lynch, Kate Wilson, Rebecca Burke, Heather Baldwin, Rachel Woodward, Alison Moren, Sue Ward, Helen Williams, Debbie Bolton, Emma Reed, Susan Ryan and Nicki Short).

Note about funding. This article presents independent research funded by the National Institute for Health Research (NIHR) under its Research for Patient Benefit (RfPB) Programme (Grant Reference Number PB-PG-0610-22005). The views expressed are those of the authors and not necessarily those of the NHS, the NIHR or the Department of Health. Trial Identifier: ISRCTN25079950 


\section{References}

Betts, N., \& Cheston, R. (2011). From warding off to working through: helping people facing a diagnosis of dementia to change their relationship with their memory problems. PSIGE Newsletter, 118, 34-42.

Cheston, R (2013) Dementia as a problematic experience: using the Assimilation Model as a framework for psychotherapeutic work with people with dementia, Neurodisability and Psychotherapy, 1 (1), 70-95.

Cheston R (2015) The role of the fear-of-loss-of-control marker within the accounts of people affected by dementia about their illness: implications for psychotherapy, in press Quaderni di Psicoterapia Cognitiva

Cheston R and Jones R (2009). A small-scale study comparing the impact of psycho-education and exploratory psychotherapy groups on newcomers to a group for people with dementia, Aging and Mental Health, 13 (3) 410-425.

Cheston, R, Jones K and Gilliard J (2004) "Falling into a hole": narrative and emotional change in a psychotherapy group for people with dementia, Dementia: the International Journal of Social Research and Policy, 3 (1), 95-103.

Cheston, R, Jones K and Gilliard J (2003) Group Psychotherapy and People with Dementia, Aging and Mental Health, 7 (6), 452-461.

Gergen K and Kaye J (1992) Beyond narrative in the negotiation of therapeutic meaning, in S, McNamee and K, Gergen Therapy as Social Construction, Sage: London.

Hermans $\mathrm{H}$ and Kempen $\mathrm{H}$ (1992) The dialogical self: beyond individualism and rationalism. American Psychologist, 47, 23-33.

Honos-Webb L, Lani J A and Stiles W B (1999) Discovering markers of assimilation stages: The fear of losing control marker. Journal of Clinical Psychology, 55, 1441-1452. 
Honos-Webb L and Stiles WB (1998) Reformulation of assimilation analysis in terms of voices, Psychotherapy, 35, 23-33.

Honos-Webb L, Surko M, Stiles W B and Greenberg L S (1998) Manual for Rating Assimilation in Psychotherapy. Unpublished manuscript, Miami University.

Honos-Webb L, Surko M, Stiles W B and Greenberg L S (1999) Assimilation of voices in psychotherapy: The case of Jan. Journal of Counselling Psychology, 46, 448-460.

Knobloch L M, Endres L M, Stiles W Band Silberschatz G (2001) Convergence and divergence of themes in successful psychotherapy: An assimilation analysis. Psychotherapy, 38, 31-39.

Lishman E, Cheston R and Smithson J (2014) The Paradox of Dementia: meaning making before and after receiving a diagnosis of dementia, Dementia: the International Journal of Social Research and Policy, published on line 27/2/14 (DOI: 10.1177/1471301214520781)

Logsdon R, Pike KC, McCurry SM, Hunter P, Maher J, Snyder L and Teri L (2010) Early-Stage Memory Loss Support Groups: Outcomes from a Randomized Controlled Clinical Trial, Journal of Gerontol B Psychol Sci Soc, November; 65B(6): 691-697.

Marshall A, Spreadbury J, Cheston R, Coleman P, Ballinger C, Mullee M, Pritchard J, Russell C and Bartlett E (2014) A Pilot Randomised Control trial to compare changes in quality of life for participants with early diagnosis dementia who attend a "Living Well with Dementia" group compared to waiting list control, Aging and Mental Health, DOI:

$10.1080 / 13607863.2014 .954527$

Newman DW and Beail N (2002) Monitoring change in psychotherapy with people with intellectual disabilities. The application of the Assimilation of Problematic Experiences Scale. Journal of Applied Research in Intellectual Disabilities, 15, 48-60. 
Robinson, L.; Clare, L.; \& Evans, K. (2005). Making sense of dementia and adjusting to loss: Psychological reactions to a diagnosis of dementia in couples. Aging and Mental Health. 9, (4) 337-347.

Sabat, S (2002). Surviving manifestation of selfhood in Alzheimer's disease. Dementia, 1, 25-36.

Snow K, Cheston R and Smart C (2014) 'Making sense' of dementia: Exploring the use of the MAPED to understand how couples process a dementia diagnosis, in press, Dementia: the International Journal of Social Research and Policy

Stiles WB(1999) Signs and Voices in Psychotherapy, Psychotherapy Research, 9, 1-21.

Stiles WB (2001) Assimilation of problematic experiences. Psychotherapy, 38, 462-465.

Stiles WB, Honos-Web L and Lani J (1999). Some functions of narrative in the assimilation of Problematic experiences, Journal of Clinical Psychology, 55, 1213-1226.

Stiles WB, Leiman M, Shapiro DA, Hardy GE, Barkham M, Detert N, and Llewelyn SP (2002). What does the first exchange tell? Dialogical sequence analysis and assimilation in very brief therapy. Psychotherapy Research, 16, 408-421.

Stiles WB, Osatuke K, Glick MJ and Mackay HC (2004) Encounters between internal voices generate emotion. An elaboration of the assimilation model. In Herman, H.H, \& Dimaggio, G. (Eds) (2004). The Dialogical Self in Psychotherapy. (pp 91-107) New York: Brunner-Routledge.

Varvin S and Stiles WB (1999) Emergence of severe traumatic experiences: An assimilation analysis of psychoanalytic therapy with a political refugee. Psychotherapy Research, 9, 381-404.

Watkins B, Cheston R, Jones K and Gilliard J (2006) "Coming out with Alzheimer's disease": changes in insight during a psychotherapy group for people with dementia, Aging and Mental Health $10(2) ; 1-11$

Watts S, Cheston R, Moniz-Cook E, et al. (2014) Post-diagnostic support for people living with dementia, in Clinical Psychology in the Early Stage Dementia Care Pathway (ed Guss, R., on 
behalf of the Faculty of the Psychology of Older People, and in collaboration with the Dementia Action Alliance), British Psychological Society, London 
Figure 1: total number of markers for all participants across the eight sessions (total of 125)

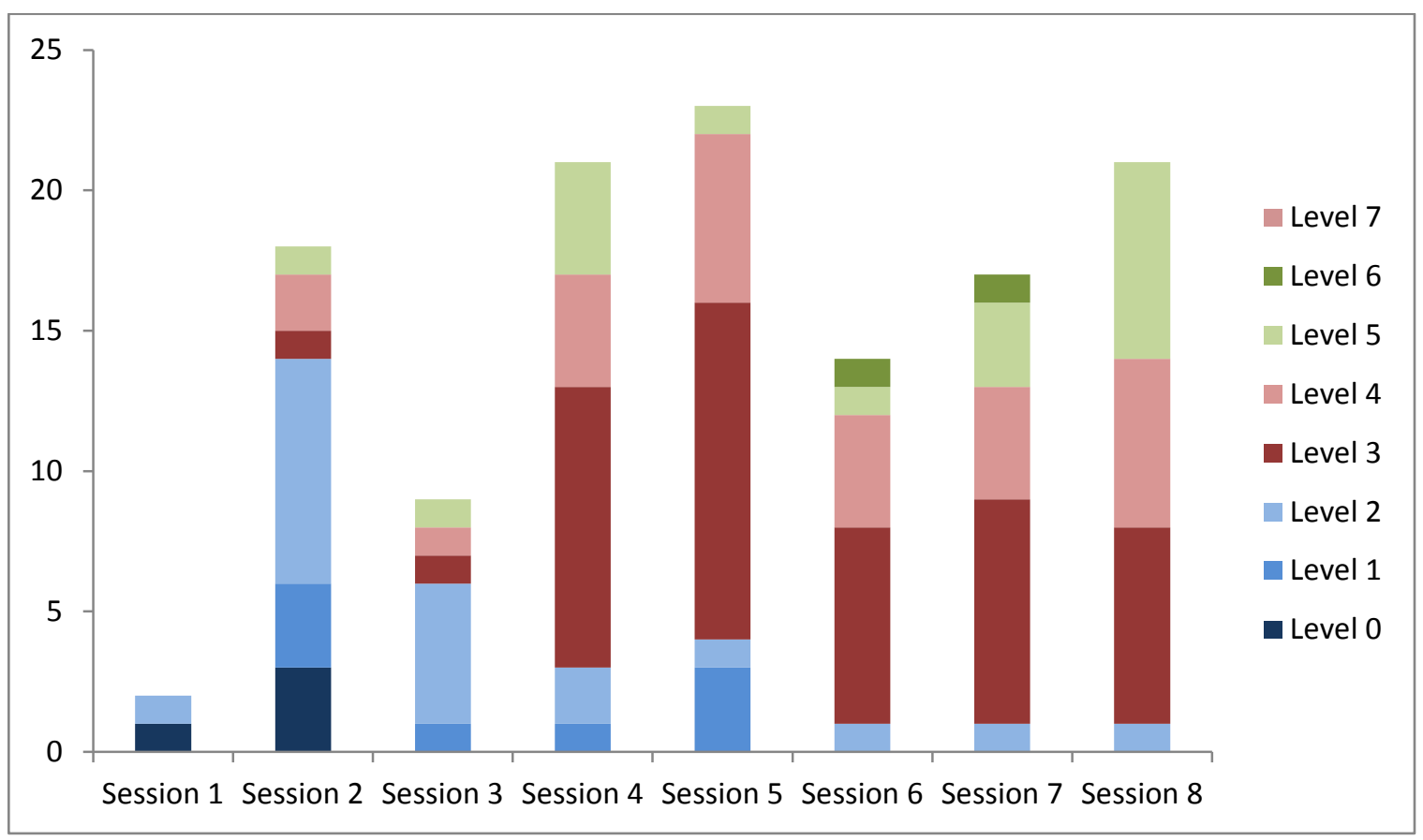

Figure 2: total number of markers for Mary, Gina and Mark across the eight sessions (total of 60)

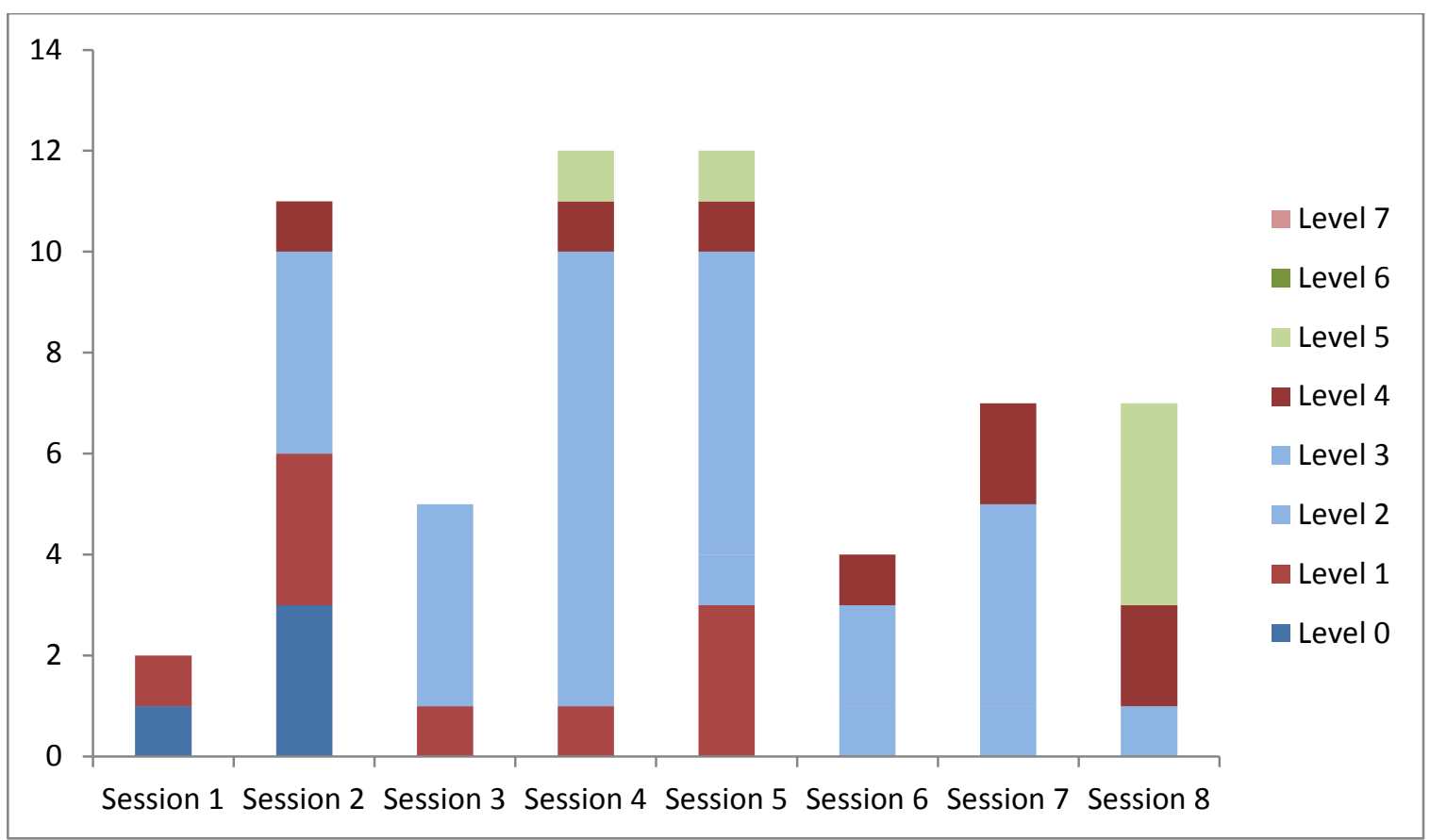


Table One: Markers of Assimilation of Problematic Experiences of Dementia Scale (MAPED)

\begin{tabular}{|c|c|c|}
\hline Assimilation level & Content and affect & Markers \\
\hline 0. Warded off & $\begin{array}{l}\text { Content is un-formed and } \\
\text { features avoidance. Minimal } \\
\text { affect, reflecting successful } \\
\text { avoidance }\end{array}$ & \\
\hline $\begin{array}{l}\text { 1. Unwanted } \\
\text { thoughts }\end{array}$ & $\begin{array}{l}\text { Emergence of thoughts } \\
\text { associated with dementia or } \\
\text { memory loss. Further discussion } \\
\text { may be avoided and dementia is } \\
\text { likely to be talked around rather } \\
\text { than named directly. Unfocused } \\
\text { strong emotions (e.g. anxiety, } \\
\text { fear, anger sadness) are more } \\
\text { salient than the content }\end{array}$ & $\begin{array}{l}\text { a) Changing the conversation } \\
\text { b) Telling a contradictory story } \\
\text { c) Fear-of- loss-of- control (e.g. } \\
\text { being mad or abnormal) } \\
\text { d) dementia is located elsewhere } \\
\text { or referred to indirectly (e.g. as } \\
\text { "it) } \\
\text { e) the significance of dementia is } \\
\text { otherwise minimised }\end{array}$ \\
\hline $\begin{array}{l}\text { 2. Vague } \\
\text { awareness }\end{array}$ & $\begin{array}{l}\text { The problematic experience of } \\
\text { dementia is acknowledged and } \\
\text { uncomfortable associated } \\
\text { thoughts are described. The } \\
\text { person is in distress, and this } \\
\text { seems to come from some } \\
\text { internal conflict relating to } \\
\text { dementia, so that in talking they } \\
\text { seem to be caught up in the } \\
\text { moment of the emotion. Affect } \\
\text { focused on acute psychological } \\
\text { pain or panic }\end{array}$ & $\begin{array}{l}\text { Expressions of } \\
\text { a) Feelings of sadness, depression, } \\
\text { worry or anxiety. } \\
\text { b) Anger or irritation about some } \\
\text { aspect of dementia } \\
\text { c) Puzzlement or confusion about } \\
\text { what is happening to them. } \\
\text { d) Feeling overwhelmed or that } \\
\text { things are getting worse. } \\
\text { e) Stories that point to the problem } \\
\text { but are not clearly described. } \\
\text { f) Use of metaphors to talk about } \\
\text { the problem }\end{array}$ \\
\hline $\begin{array}{l}\text { 3. Problem } \\
\text { statement or } \\
\text { clarification }\end{array}$ & $\begin{array}{l}\text { The person acknowledges the } \\
\text { existence of dementia as a } \\
\text { problem and attributes this to an } \\
\text { illness such as dementia. Affect is } \\
\text { negative but manageable }\end{array}$ & $\begin{array}{l}\text { a) Describing their reaction to } \\
\text { dementia, which may include } \\
\text { mixed feelings (e.g. "yes .... But") } \\
\text { b) The person appears 'stuck' and } \\
\text { sees no way out. } \\
\text { c) Developing a clearer } \\
\text { understanding of dementia (e.g. } \\
\text { asking questions or being } \\
\text { curious) } \\
\text { d) Describing contradictions in the } \\
\text { illness } \\
\text { e) Describing that previous } \\
\text { difficulties in recognising the } \\
\text { problem }\end{array}$ \\
\hline $\begin{array}{l}\text { 4. Understanding/ } \\
\text { insight }\end{array}$ & $\begin{array}{l}\text { The person acknowledges the } \\
\text { existence of dementia and is able } \\
\text { to describe how this makes them } \\
\text { feel, or how they react to this. } \\
\text { They are able to stand back from } \\
\text { their feelings. Curiosity of affect, } \\
\text { with mixed pleasant and }\end{array}$ & $\begin{array}{l}\text { a) Describing situations where their } \\
\text { feelings differ in intensity } \\
\text { b) Emotional distance from the } \\
\text { dementia (e.g. through use of } \\
\text { humour) } \\
\text { c) Making links between dementia } \\
\text { and others areas of their life }\end{array}$ \\
\hline
\end{tabular}




\begin{tabular}{|c|c|c|c|}
\hline & unpleasant recognitions & d) & $\begin{array}{l}\text { Making links between the past } \\
\text { and the present } \\
\text { Comparing themselves with } \\
\text { others in a worse position }\end{array}$ \\
\hline $\begin{array}{l}\text { 5. Application/ } \\
\text { working } \\
\text { through }\end{array}$ & $\begin{array}{l}\text { The person both acknowledges } \\
\text { the existence of a dementia and } \\
\text { can also point out what needs to } \\
\text { get worked on. Business-like } \\
\text { positive affect that is optimistic } \\
\text { or hopeful and linked to } \\
\text { strategies }\end{array}$ & b) & $\begin{array}{l}\text { Weighing up attempts at a } \\
\text { partial solution to the problem } \\
\text { (e.g. taking medication). } \\
\text { Acknowledging deterioration } \\
\text { and explicitly describing some } \\
\text { acceptance. }\end{array}$ \\
\hline 6. $\begin{array}{l}\text { Problem } \\
\text { solution }\end{array}$ & $\begin{array}{l}\text { The person acknowledges that } \\
\text { they have a dementia, and have } \\
\text { achieved a successful solution for } \\
\text { a specific problem. They } \\
\text { recognise change in their lives. } \\
\text { Affect includes positive } \\
\text { satisfaction or pride linked to } \\
\text { accomplishments }\end{array}$ & c) & $\begin{array}{l}\text { Achieving a change in their life in } \\
\text { living with the dementia that } \\
\text { they feel positive about. } \\
\text { Change in their understanding of } \\
\text { what is happening to them or } \\
\text { their relationships with others } \\
\text { Comments on how others have } \\
\text { noticed that they have changed }\end{array}$ \\
\hline 7. Mastery & $\begin{array}{l}\text { The person is able to integrate } \\
\text { dementia into the whole of their } \\
\text { life. Dementia is acknowledged } \\
\text { and recognised but no longer } \\
\text { defines them as a person. Affect } \\
\text { is neutral (i.e. this is no longer } \\
\text { something to get excited about) }\end{array}$ & a) & $\begin{array}{l}\text { The person successfully uses } \\
\text { their new solutions in new } \\
\text { situations }\end{array}$ \\
\hline
\end{tabular}


Table 2: Structure of Living Well with dementia intervention

\begin{tabular}{|c|c|c|c|}
\hline Week & Attended by & Title of session & Content \\
\hline Preliminary & $\begin{array}{l}\text { Participants and } \\
\text { carers }\end{array}$ & $\begin{array}{l}\text { Welcome and } \\
\text { Introductions }\end{array}$ & $\begin{array}{l}\text { Introduction to the group and to } \\
\text { other participants, familiarisation } \\
\text { with structure, discussion of } \\
\text { recovery model }\end{array}$ \\
\hline One & Participants & $\begin{array}{l}\text { Problems and } \\
\text { frustrations }\end{array}$ & $\begin{array}{l}\text { Introduction, group rules and } \\
\text { icebreaker exercise. Participants } \\
\text { identify problems associated with } \\
\text { memory loss. }\end{array}$ \\
\hline Two & Participants & $\begin{array}{l}\text { Memory Aids and } \\
\text { Strategies }\end{array}$ & $\begin{array}{l}\text { Description of nature of short-term } \\
\text { memory loss - compared to filing } \\
\text { letters in a filing cabinet. } \\
\text { Discussion of strategies for } \\
\text { compensating for problems }\end{array}$ \\
\hline Three & Participants & $\begin{array}{l}\text { Finding a way through } \\
\text { feelings }\end{array}$ & $\begin{array}{l}\text { Discussion of emotional impact of } \\
\text { memory problems and other } \\
\text { cognitive symptoms. Impact of the } \\
\text { problems on the wider system }\end{array}$ \\
\hline Four & Participants & Coping with stress & $\begin{array}{l}\text { Discussion of the impact of anxiety } \\
\text { on memory loss. Relaxation } \\
\text { exercise during session, and } \\
\text { participants given a relaxation CD }\end{array}$ \\
\hline Five & Participants & $\begin{array}{l}\text { Friends and family, } \\
\text { health professionals and } \\
\text { strangers }\end{array}$ & $\begin{array}{l}\text { Impact of dementia on social } \\
\text { systems discussed, including issues } \\
\text { about whether to tell others about } \\
\text { the diagnosis }\end{array}$ \\
\hline Six & Participants & What is dementia? & $\begin{array}{l}\text { Focuses on the process and } \\
\text { assessment and diagnosis. } \\
\text { Information about different types } \\
\text { of dementia, treatment and } \\
\text { choices (e.g. driving) }\end{array}$ \\
\hline Seven & Participants & Living as well as you can & $\begin{array}{l}\text { Importance of healthy lifestyle - } \\
\text { diet and preparing for the future }\end{array}$ \\
\hline
\end{tabular}


Assimilation analysis of LivDem therapy groups

\begin{tabular}{|l|l|l|l|}
\hline Eight & Participants & Staying active & $\begin{array}{l}\text { Social contacts and activity. saying } \\
\text { goodbye to the group, revisiting } \\
\text { initial hopes and expectations }\end{array}$ \\
\hline Consolidation & $\begin{array}{l}\text { Participants and } \\
\text { carers }\end{array}$ & $\begin{array}{l}\text { Bringing it all back } \\
\text { together }\end{array}$ & \\
\hline
\end{tabular}


Table 3: demographic and outcome scores for group participants

\begin{tabular}{|l|c|c|c|c|}
\hline & Age & Diagnosis & $\begin{array}{c}\text { Previous } \\
\text { occupation }\end{array}$ & Marital status \\
\hline Ellen & 87 & Vascular dementia & Housewife & Married \\
\hline Graham & 74 & Alzheimer's disease & Civil servant & Married \\
\hline Mark & 51 & Alzheimer's disease & Plumber & Single \\
\hline Gina & 82 & Mixed dementia & Nurse & Widowed \\
\hline Mary & 66 & Vascular dementia & Shop Assistant & Divorced \\
\hline
\end{tabular}

